\title{
Numerical Research on the Effect of Impactor Shape and Core Characteristics on the Ballistic Impact Response of Marine Sandwich Composite Plates
}

\author{
Mahesh.C, Rajesh P Nair
}

\begin{abstract}
The dynamic response of composite plates to impactors of different shapes is investigated. In this paper simulation of the responses of several composite sandwich plates made of glass fiber skins and cores made of polypropylene honeycomb as well as foam 81 are subjected to impact dynamic loads of steel impactors of shapes flat, hemi spherical and conical are evaluated and compared. The kinetic energy loss of the projectile during the impact is the criteria used to compare the different types of impactors. Also comparative analysis of sandwich composite plates made of honeycomb core and foam core is done. It is also found that target energy absorption value changes during the impact process when the layer angle of the glass fiber skin changes. The numerical analysis was performed using FEM (ANSYS software)
\end{abstract}

Keywords: ballistic impact, foam, honeycomb, sandwich structures

\section{INTRODUCTION}

A sandwich-structured composite is a special class of composite materials that is fabricated by attaching two thin but stiff skins to a lightweight but thick core[1]. The core material is normally low strength material, but its higher thickness provides the sandwich composite with high bending stiffness with overall low density. The composites have a higher stiffness and strength by weight compared to other materials such as steel, wood, aluminum etc. Nowadays composite materials are extensively used in ship building. Noury et al. [2] presented recent advances in lightweight construction for modern shipbuilding.

Arbaoui et al. [3] studied about the effect of core thickness and intermediate layers on the mechanical properties of a polypropylene honeycomb core/composite facing multilayer sandwich structure under three points bending. From the experimental and analytical study they found that the mechanical properties of the composites increase with increase in thickness of the cores .But no high velocity impact test was done in that study. Brenda et al.[4] studied the impact behavior of the sandwich panels made out

of carbon fibers with core of aluminum 3000. Abrate[5] investigated the needed speed of a projectile to penetrate the panels made out of layered composites and sandwich. Jian $\mathrm{He}$ et al.[6] have studied the impact resistance of fiber reinforced composite laminates using the kinetic energy loss criterion. In a recent study, Rotaru et al.[7] has done an extensive work on impact rate evaluation of sandwich composites used in ship building

In this paper, the comparative analysis of projectiles of different geometric shapes are done, and also dynamic response of sandwich composite plates made of polypropylene honey comb as well as SAN foam 81 cores are studied. Epoxy E-glass fiber is used as the skin for both type of cores. Also in the current study, it is proved numerically that the ballistic resistance of the sandwich composite material increases with the increase in the thickness of the core.

From the available literature it is found that ballistic resistance of a target material is directly proportional to the increase in internal energy $(\Delta \mathrm{E})$ of the target or decrease in kinetic energy $(\triangle \mathrm{KE})$ of the projectile (impactor). In this investigation both the criteria are used to measure the ballistic impact resistance of composite sandwich plates. Velocities ranging from $45 \mathrm{~m} / \mathrm{s}$ to $75 \mathrm{~m} / \mathrm{s}$ are given to the projectiles for the impact evaluation process.

\section{SANDWICH COMPOSITE PANEL}

Sandwich composite plates used in the study consists of two types of cores, polypropylene honeycomb and SAN foam 81. On both sides of the core a thin layer of Epoxy E-glass fiber is used as the skin, with a total thickness of $1 \mathrm{~mm}$. This $1 \mathrm{~mm}$ thickness consists of 3 number of $.33 \mathrm{~mm}$ thick layers. The core is usually much thicker compared to the skins. The schematic diagram of a sandwich panel with honeycomb core is shown in fig. 1

\section{MATERIAL PROPERTIES}

Usually high density materials are used as the core and low density materials are used as the skin. The materials used in 
the current study are shown in tableI.

Table I. Material properties

\begin{tabular}{|l|l|}
\hline Material used & $\begin{array}{l}\text { Density } \\
\left(\mathbf{K g} / \mathbf{m}^{3}\right)\end{array}$ \\
\hline EpoxyE-glass & $2 \times 10^{3}$ \\
\hline Honeycomb(Polypropylene) & 80 \\
\hline Foam (Polystyrene) & 81 \\
\hline Structural steel & 7850 \\
\hline
\end{tabular}

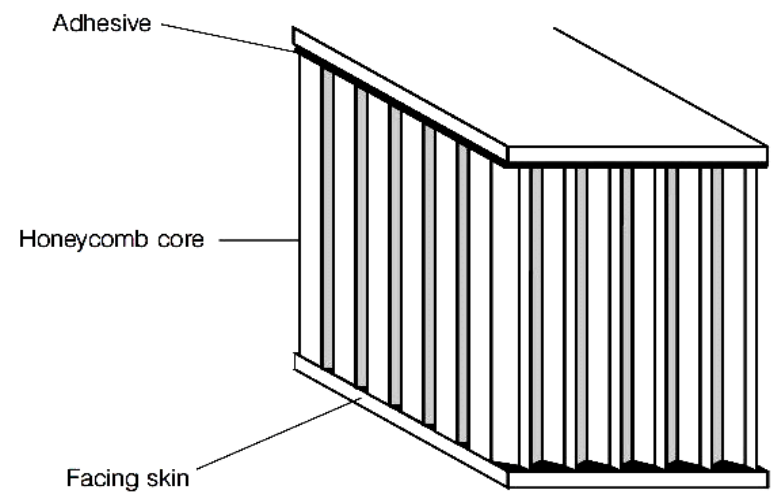

Sandwich panel

Fig1. Sandwich composite panel

\section{RESULTS AND DISCUSSION}

All the analysis are done numerically and $\mathrm{ACP}(\mathrm{pre})$ solver from ANSYS 16.2 is used for making the sandwich composite plates and the analyses are done by ANSYS AUTODYN PrePost

A. Comparative analysis of impactor shapes on the dynamic response of sandwich plates

Impactors with three different geometric shapes are used for the ballistic impact on the sandwich plates. The impactor shapes are flat, hemispherical and conical as shown in fig.2.The type of sandwich plate used is having a $15 \mathrm{~mm}$ thick honeycomb core and $1 \mathrm{~mm}$ thick Epoxy E- glass fibre on both sides of the core. The $1 \mathrm{~mm}$ thick E-glass layer consists of 3 number of $.33 \mathrm{~mm}$ thick layers. The diagrammatic sketch is shown in fig. 3

TableII shows the kinetic energy loss of the impactors during the ballistic impact. The energy loss is calculated at six different velocities i.e. $45 \mathrm{~m} / \mathrm{s}, 50 \mathrm{~m} / \mathrm{s}, 55 \mathrm{~m} / \mathrm{s}, 60 \mathrm{~m} / \mathrm{s}$, $65 \mathrm{~m} / \mathrm{s}$ and $70 \mathrm{~m} / \mathrm{s}$ respectively.
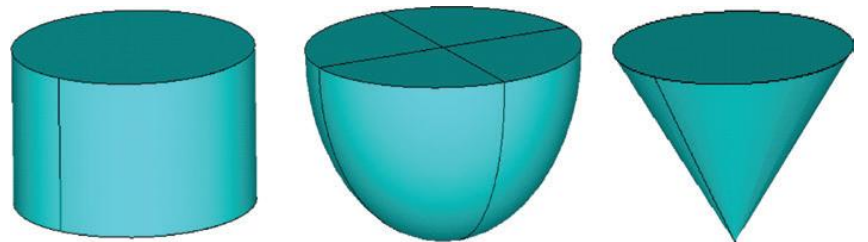

Fig.2 Flat, hemispherical and conical impactors
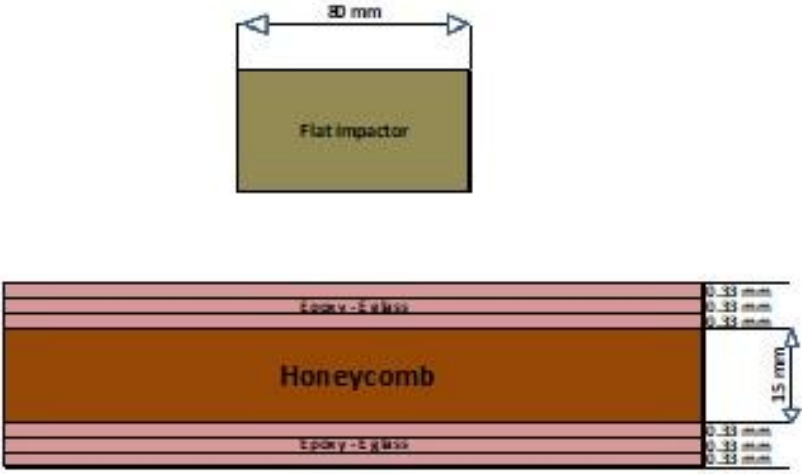

Fig3.Flat projectile hitting a sandwich composite

TableII: Kinetic energy loss during the impact

\begin{tabular}{|l|l|l|l|}
\hline $\begin{array}{l}\text { Velocity } \\
(\mathbf{m} / \mathbf{s})\end{array}$ & $\begin{array}{l}\text { Hemispherical } \\
\boldsymbol{\Delta K E ( J )}\end{array}$ & $\begin{array}{l}\text { Conical } \\
\Delta K E(J)\end{array}$ & $\begin{array}{l}\text { Flat } \\
\Delta \text { KE(J) }\end{array}$ \\
\hline 45 & 247 & 361 & 153 \\
\hline 50 & 275 & 423 & 170 \\
\hline 55 & 303 & 488 & 196 \\
\hline 60 & 336 & 543 & 224 \\
\hline 65 & 369 & 616 & 265 \\
\hline 70 & 377 & 682 & 302 \\
\hline
\end{tabular}

The variation in the kinetic energy loss with velocity for hemispherical, conical and flat projectiles are shown in fig4. More kinetic energy loss of the projectile more means, the target plates absorbs more internal energy during the impact process. Thus the effect on the target plate will be less during the impact and it will cause less damage on the plate compared to projectiles with less kinetic energy loss. From the graph it is evident that conical projectile is having the highest energy loss and flat projectile is having the lowest energy loss at all impact velocities. So flat projectile is more destructive in nature compared to conical and hemispherical ones.

kinetic energy loss of impactors at various velocities

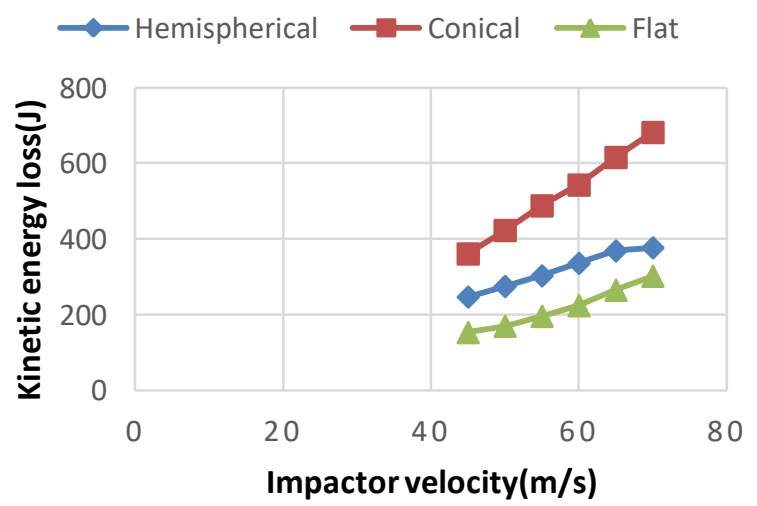

Fig.4. Energy loss of impactors during high velocity impact 
The deformation of the sandwich plate with a flat shaped impactor is shown in fig. 5

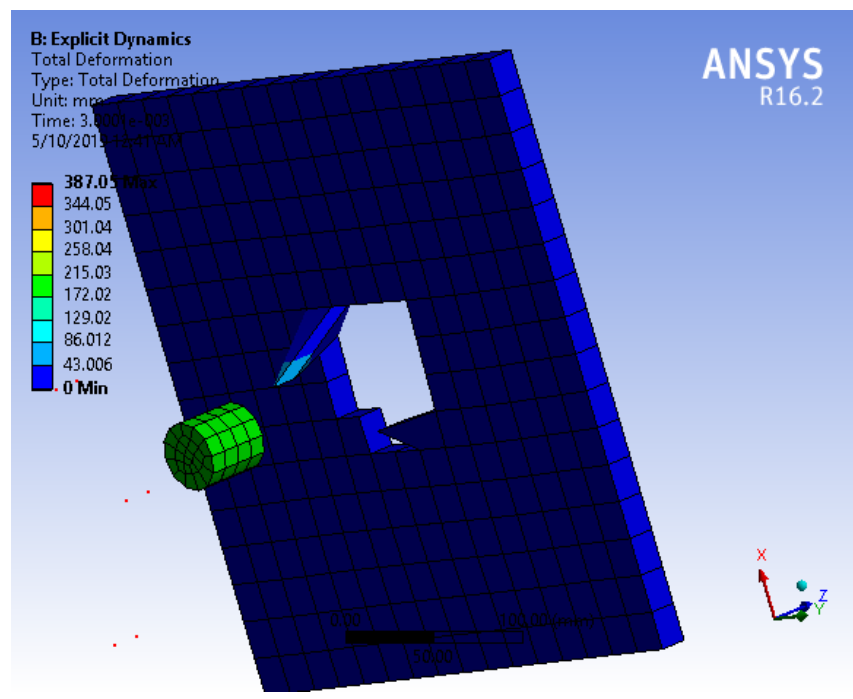

Fig5. Plate deformation with the flat impactor

B. Comparative analysis of sandwich composites made of honeycomb core and foam core

Here two cases are analyzed. In the first case sandwich composite plates with honeycomb core and foam cores of same thickness are impacted with projectiles of different geometric shapes. And in the second case sandwich plates made of honeycomb core and foam core of different core thickness are studied during the impact with a flat nose shaped projectile.

Case 1: Sandwich plates of same core thickness under impactors of different geometric shapes

When sandwich plates made of honeycomb core of $15 \mathrm{~mm}$ thickness and foam core of same thickness are impacted with a hemispherical projectile, the energy absorption details of the plates are shown in fig. 6

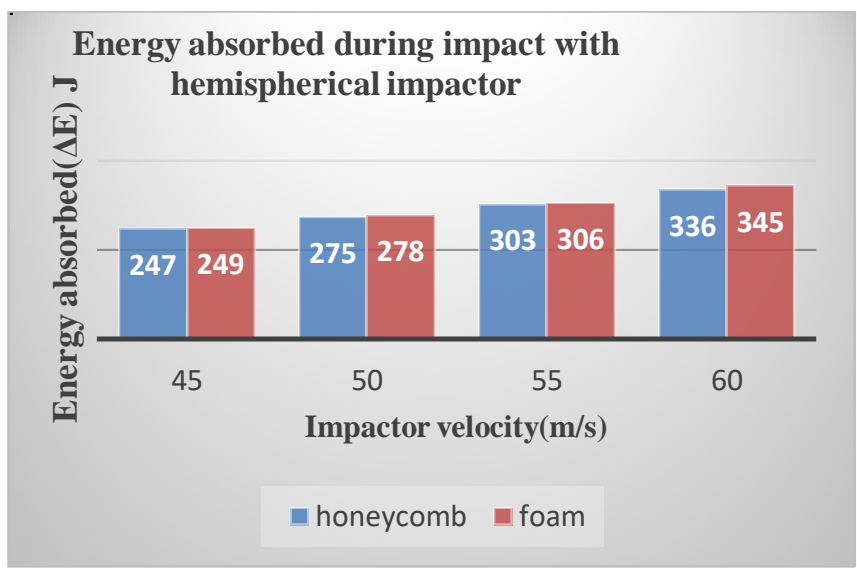

Fig6.Energy absorbed during impact with a hemispherical projectile

From the graph it is evident that at all velocities foam core is absorbing more energy compared to honeycomb core. Even though the difference is very small, it can be inferred that foam core is having better ballistic properties compared to honeycomb.

Fig.7 and fig.8 show the results of ballistic impact with conical and flat impactor respectively. They also show that sandwich composites with foam core are better against ballistic impact compared to honeycomb sandwich composites

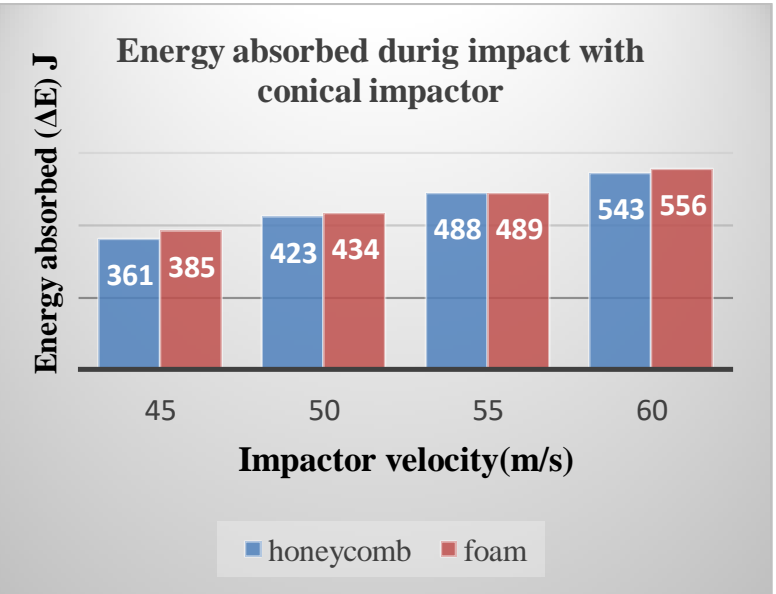

Fig7.Energy absorbed during impact with a conical projectile

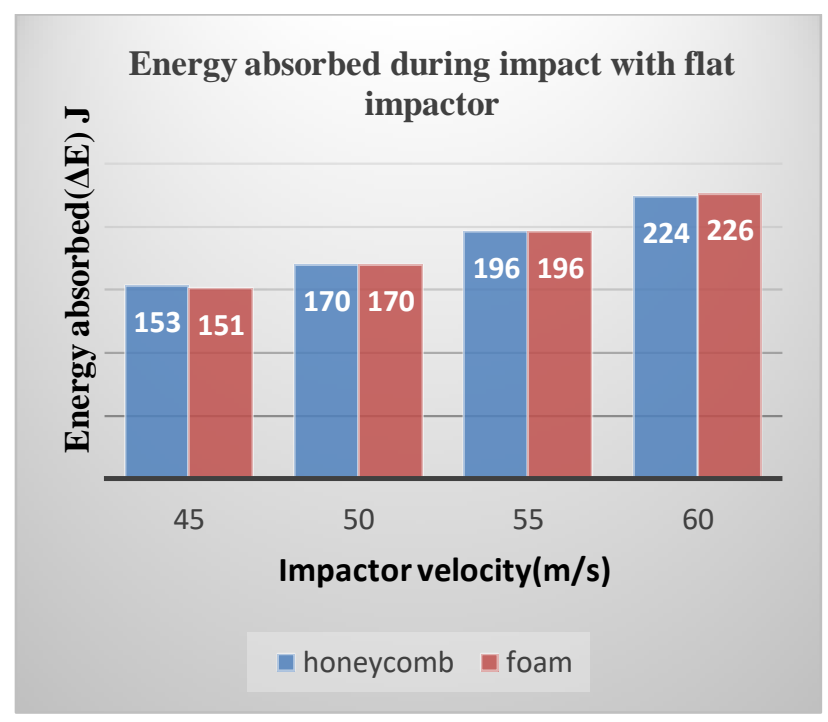

Fig.8. Energy absorbed during impact with a flat projectile

Case 2: Sandwich plates of different core thicknesses under impactor of same geometric shape

In this case, to compare honeycomb and foam, different core thicknesses of $10 \mathrm{~mm}, 15 \mathrm{~mm}, 20 \mathrm{~mm}$ and $25 \mathrm{~mm}$ are used for both honeycomb and foam. The plates are impacted with a flat projectile of velocity $75 \mathrm{~m} / \mathrm{s}$. The results are shown in tableIII. 
Table III.Energy absorption at different core thicknesses

\begin{tabular}{|r|r|r|}
\hline \multicolumn{1}{|l|}{$\begin{array}{l}\text { Core } \\
\text { thickness } \\
(\mathbf{m m})\end{array}$} & \multicolumn{2}{|c|}{$\begin{array}{c}\text { Honeycomb } \\
\boldsymbol{\Delta E}(\mathbf{J})\end{array}$} \\
\hline 10 & 340 & \multicolumn{2}{|c|}{$\mathbf{\Delta \mathbf { E } ( \mathbf { J } )}$} \\
\hline 15 & 342 & 342 \\
\hline 20 & 367 & 343 \\
\hline 25 & 392 & 369 \\
\hline & & 394 \\
\hline
\end{tabular}

Figure9 shows the comparison of energy absorption values of honeycomb and foam at different core thicknesses. From the graph it is verified that at all these thicknesses sandwich composites made of foam cores are slightly better in ballistic properties compared to sandwich composites made of honeycomb core.

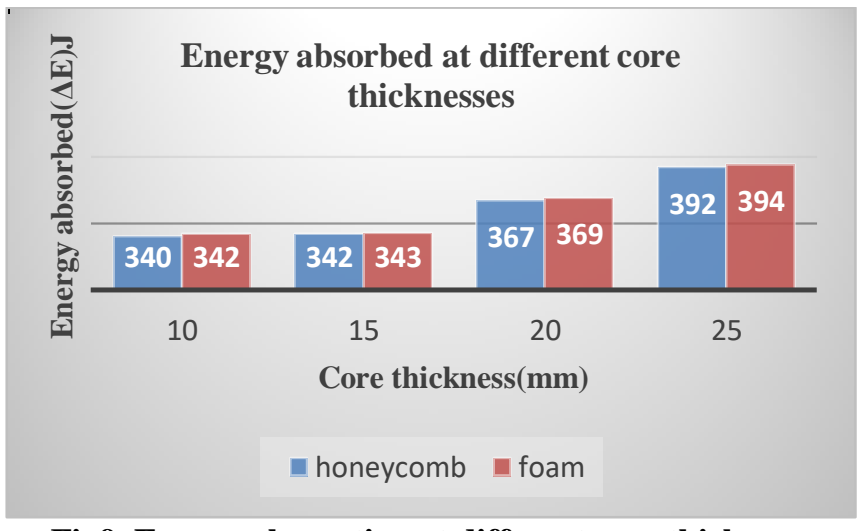

Fig9. Energy absorption at different core thicknesses

Arbaoui[3] used bending test to show that mechanical properties increase with increase in core thickness. The mechanical properties measured in that study were facing stress, core shear stress, bending stiffness, shear modulus shear stiffness etc.But no high velocity impact on sandwich composites was done in that study.

C. Effect of ply angle on target plate energy absorption during ballistic impact

The skin of the sandwich composite laminate consists of a number of layers bonded together by resign in the thickness direction. Properties of the laminate can be altered by orientation of fibers in each lamina. In this study, sandwich skin thickness of $1 \mathrm{~mm}$ consists of 3 layers of $.33 \mathrm{~mm}$ thick layers are used as shown in fig.3.

Table IV. Energy absorbed at different ply angles

\begin{tabular}{|r|r|}
\hline $\begin{array}{l}\text { ply angle } \\
\text { (degree) }\end{array}$ & $\Delta \mathrm{E}(\mathrm{J})$ \\
\hline 0 & 116 \\
\hline 15 & 88 \\
\hline 30 & 126 \\
\hline 45 & 94 \\
\hline 60 & 85 \\
\hline 75 & 96 \\
\hline 90 & 83 \\
\hline
\end{tabular}

Jian He et.al [6] analyzed the relationship between ply angle and target plate energy absorption in the case of composite laminates. They studied the impact response of the panels at $0^{\circ}, 30^{\circ}, 45^{\circ}$ and $90^{\circ}$ angles and found that highest kinetic energy loss for the projectile happens at $0^{0}$ angle.

In the current study when the ply angle is changed from $0^{0}$ to $90^{\circ}$ at equal intervals the resulted energy absorption is shown in table IV. The fig.10 is the graph showing the relationship between ply angle and energy absorption of the composite. From the graph it can be seen that the energy absorption of the plate changes with change in ply angle and maximum energy absorption happens at $30^{\circ}$ ply angle. It is due to the fact that when the ply angle changes, the strain rate strengthening effects also changes.

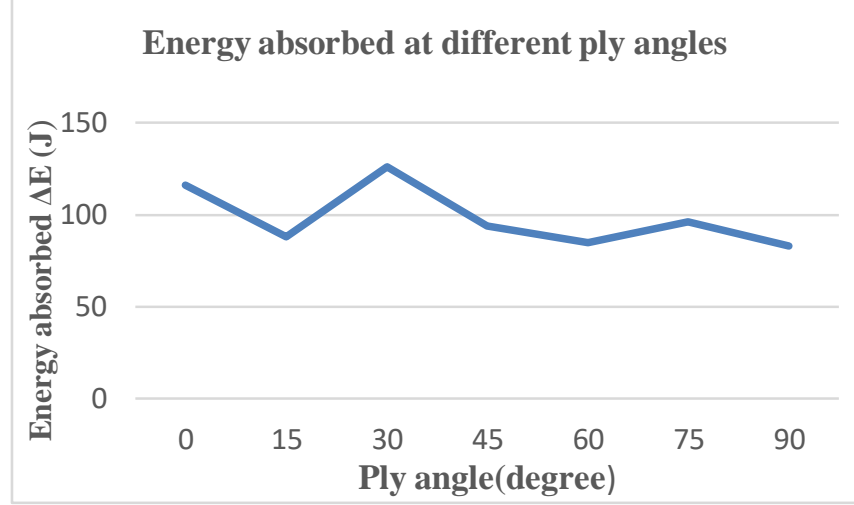

Fig.10.Energy absorbed at different ply angles

E-glass layer at $30^{\circ}$ ply angle, constructed in ANSYS $\mathrm{ACP}(\mathrm{Pre})$ is shown in fig. 11
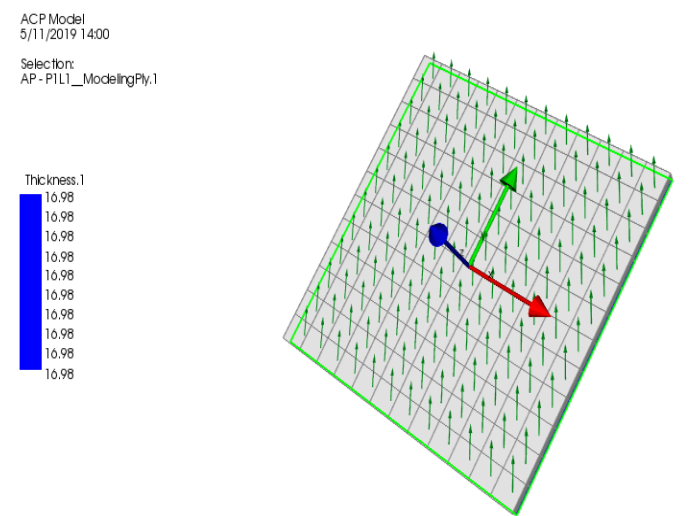

ANSYS

Fig11. E-glass fiber layer at 300 ply angle

\section{CONCLUSION}

In this paper, the dynamic response of sandwich composite laminates are simulated under high velocity impacts. Under high velocity impacts the loss of kinetic energy of the projectiles and increase in internal energy of the composite plates are evaluated and compared. Results show that energy absorption of the plates increases linearly with increase in velocity of impact. And as the core thickness increases, the energy absorption increases non linearly. 
When three projectiles of different geometric shapes are analyzed, it is found that projectile with flat shape is the better impactor compared to conical and hemispherical ones

In the comparative analysis of sandwich composite laminates made of polypropylene honeycomb core and SAN foam 81 core, the performance of the latter one is having better resistance against bullet penetration irrespective of bullet nose shape and target core thickness.

\section{REFERENCES}

1. Andrew C.Marshall, "Chapter 12- Sandwich Construction", Handbook Composites, Springer, 1998.

2. Noury P., Hayman B., McGeorge D., Weitzenbock J.: Lightweight Construction for Advanced Shipbuilding RecentDevelopment. DNV internal report, 2002

3. Arbaoui.J, Schmitt.Y, Pierrot.J.L,Royer.F.X, "effect of core thickness and intermediate layers on mechanical properties of polypropylene honeycomb multi-layer sandwich structures", Archives of metallurgy and materials engineering, Vol 59,2014

4. Brenda L., Santiuste C., Sanchez-Saez S., Barbereo E., Navarro C., Modeling of composite sandwich structures with honeycomb core subjected to high-velocity impact, Madrid, Spain.

5. Abrate,S., Ballistic Impacts on Composite and Sandwich Structures, Major Accomplishments in Composite Materials and Sandwich Structures, Vol.IV, pp. 465-501, 2010

6. Jian He, Liang He, and Bin Yang Analysis on the impact response of fiber-reinforced composite laminates: an emphasis on the FEM simulation, Sci Eng Compos Mater 2019; $1-11$

7. Rotaru,F Chirică,I Beznea.E.F Impact rate evaluation of composite sandwich plates used in sshipbuilding, la conferința "Computational mechanics and virtual engineering" COMEC 2015, Brașov; BDI 